Annals of International Medical and Dental Research

E-ISSN: 2395-2822 | P-ISSN: 2395-2814

Vol-8, Issue-1 | January-February 2022

DOI: $10.53339 /$ aimdr.2022.8.1.17

Page no- 124-131 | Section- Research Article (Gastroenterology)

\title{
Clinical profile of patients with esophageal carcinoma: A multicentric study from North India
}

\author{
Saurabh Singh¹, Paraag Kumar2*, Gurpreet Kaur Chawla ${ }^{3}$, Meenu Gupta ${ }^{4}$, Anuradha Kusum ${ }^{5}$
}

\begin{abstract}
${ }^{1}$ Assistant Professor, Department of Gastroenterology, Himalyan Institute of Medical Sciences, Jolly Grant, Dehradun, Uttarakhand, India. Email: Drsingh.saurabh@gmail.com Orcid ID: 0000-0001-7513-4220

${ }^{2}$ Assistant Professor, Department of Gastroenterology, MMIMSR, Mullana, Ambala, Haryana, India. Email: paraag2789@gmail.com Orcid ID: 0000-0002-9192-3577

Intern, Department of Gastroenterology, Himalyan Institute of Medical Sciences, Jolly Grant, Dehradun, Uttarakhand, India.

Email: gurpreetchawla311@gmail.com

Orcid ID: 0000-0003-0489-3523

4Professor and Head, Department of Radiation Oncology, Himalyan Institute of Medical Sciences, Jolly Grant, Dehradun, Uttarakhand, India. Email: meenugupta@srhu.edu.in

Orcid ID: 0000-0002-7131-4408

5Professor, Department of Pathology, Himalyan Institute of Medical Sciences, Jolly Grant, Dehradun, Uttarakhand, India.

Email: anuradhakusum@srhu.edu.in

Orcid ID: 0000-0003-4439-6038
\end{abstract}

*Corresponding author

Received: 01 October 2021

Revised: 16 November 2021

Accepted: 23 November 2021

Published: 22 December 2021

\begin{abstract}
Background: Carcinoma esophagus is the 6th most common cancer in India with an incidence of 5.04\% It most commonly affects older age individuals, with incidence peaking in seventh and eighth decades of life. Adenocarcinoma (AC) and Squamous cell carcinoma (SCC) are the two main histological variants. Our aim was to study the risk factors, clinical and epidemiological profile of patients diagnosed with Esophageal Cancer from two tertiary care centres located in North India. Methods: This was a retrospective study carried in departments of gastroenterology of two tertiary care hospitals North India. Data was collected from respective institutes for the previous 1 year i.e. from 1st October 2020 to 30th September 2021. All patients presenting to Gastroenterology OPD or emergency with dysphagia who were diagnosed as having Carcinoma esophagus were included in the study. Results: A total of 106 patients were included in this study. There were 44 females \& 66 males. The most common presenting complaint was Dysphagia (48\%) followed by Loss of weight $(26.4 \%)$, Vomiting (in 23.6\%) and Odynophagia (22.6\%). Involvement of the lower one third of the oesophagus was the most common (37.7\%). SCC (Squamous Cell Carcinoma) was the most common type of oesophageal carcinoma in this study, seen approximately in $80 \%$ of cases. Conclusion: Our study from North India suggested poor oral hygiene as a strong risk for carcinoma esophagus Males were more commonly affected and SCC was the predominant variant.
\end{abstract}

Keywords:- Carcinoma esophagus, Adenocarcinoma, Squamous Cell Carcinoma.

\section{INTRODUCTION}

Esophageal cancer is among the top 10 most commonly occurring malignancies in the world.11] It most commonly affects older age individuals, with incidence peaking in seventh and eighth decades of life. As per the WHO
Globocon 2018, Carcinoma esophagus is the 6th most common cancer in India with an incidence of $5.04 \%$. It is more common in males than females with a male:female ratio of 2.4:1.2] In karnatka, Tamil Nadu, Kerala and Assam, it is the most common gastrointestinal 
Annals of International Medical and Dental Research

E-ISSN: 2395-2822 | P-ISSN: 2395-2814

Vol-8, Issue-1 | January-February 2022

DOI: $10.53339 /$ aimdr.2022.8.1.17

Page no- 124-131 | Section- Research Article (Gastroenterology)

malignancy.[3] A very high incidence has also been reported from Kashmir valley.[4] Incidence of esophageal cancer has been on the rise worldwide, specially adenocarcinoma.[5] Esophageal cancer has shown to exhibit significant regional variation in incidence and pathology. Adenocarcinoma (AC) and Squamous cell carcinoma (SCC) are the two main histological variants. Sarcomas or small cell carcinomas account for less than $1 \%$ to $2 \%$ of all esophageal cancers.[6] SCC can occur anywhere along the entire length of esophagus as squamous epithelium is present throughout the esophagus. Adenocarcinoma usually arises from the lower esophagus following barrett's esophagus which has intestinal metaplasia.[7] The 5-year survival rate for all patients diagnosed with esophageal cancer still ranges from $15 \%$ to $20 \%$, despite many advances in diagnosis and treatment.[8] Previous studies carried out in India generally report a single centre experience. This study was aimed to review the risk factors, clinical and epidemiological profile of patients diagnosed with Esophageal Cancer from two tertiary care centres located in North India.

\section{MATERIAL AND METHODS}

This was a retrospective study carried in departments of gastroenterology of two tertiary care hospitals. Data was collected from Maharishi Markandeshwar Institute of Medical Sciences \& Research (MMIMSR), MullanaAmbala, Haryana and Himalyan Institue of Medical Sciences, Jolly Grant, Dehradun. Data was collected from respective institutes for the previous 1 year i.e. from 1st October 2020 to 30th September 2021.

\section{Inclusion Criteria}

All patients presenting to Gastroenterology OPD or emergency with dysphagia who were diagnosed as having Carcinoma esophagus were included in the study.

Detailed clinical history including dysphagia, odynophagia, recurrent vomitings was recorded. Blood investigations like complete blood count (CBC), liver function test (LFT), renal function test (RFT), random blood sugars were noted from the record files. Various radiological investigations eg ultrasound abdomen, CT abdomen and /or Barium swallow were also included in the data. Upper GI endoscopy reports were noted including the biopsy reports.

For descriptive statistical analysis, mean, standard deviation, and frequencies were calculated. Different characteristics were represented as numbers or percentage wherever required. Statistical analysis was done by statistical software SPSS for Windows v22.0 (SPSS, Chicago, IL, USA). Comparisons between groups were performed using the Student t-test or the Mann-Whitney U test for continuous variables and the chi-square test $(\chi 2)$ or the Fisher exact test for categorical data. $\mathrm{P}-$ Value shows the significance level $(\mathrm{p}<0.05$ or $\mathrm{p}<0.001$ ).

\section{RESULTS}

A total of 106 patients including 44 females $(37.7 \%)$ and 66 males $(62.3 \%)$ were enrolled in this study. The mean age of the patients was $56.5 \pm 13.4( \pm \mathrm{SD})$ years with age range of 21 to 85 years. 
Annals of International Medical and Dental Research

E-ISSN: 2395-2822 | P-ISSN: 2395-2814

Vol-8, Issue-1 | January-February 2022

DOI: $10.53339 /$ aimdr.2022.8.1.17

Page no- 124-131 | Section- Research Article (Gastroenterology)

There was increasing incidence of Carcinoma oesophagus with advancing age. In the age group of 20-30 years, 31-40 years, 41-50 years, 51-60 years \& $>60$ years there were $3.8 \%(n=4)$, $10.4 \%(n=11), 17 \%(n=18), 32.1 \%(n=34) \& 36.8 \%$ $(\mathrm{n}=39)$ of patients respectively . Maximum patients $(n=39)$ belonged to age group of 60 years and above. However, $70 \%$ of patients belonged to age group of 50 years and above. Most of the patients were from lower income group.

The most common presenting complaint was Dysphagia (48\%) followed by Loss of weight $(26.4 \%)$, Vomiting (23.6\%) and Odynophagia $(22.6 \%)$. Haemetemesis was also seen in $15 \%$ of cases. There were no consistent pattern of diet intake regarding vegetarian and nonvegetarian food, dietary habits and eating pattern, alcohol intake, treatment history for dyspepsia.

Majority of the patients $(75 \%)$ had poor oral hygiene and dental disease which might be identified as most common risk factor. Smoking was second most common risk factor identified in 43 patients ( $40.6 \%)$. The clinical profile has been given in Table I.

Involvement of the lower one third of the oesophagus was the most common $(37.7 \%)$ in patients presenting with carcinoma oesophagus followed by middle third (35.8\%) then upper one-third (26.4\%). SCC (Squamous Cell Carcinoma) was the most common type of oesophageal carcinoma in this study, seen approximately in $80 \%$ of cases $(n=85)$. Adenocarcinoma was seen in rest $20 \%$ of cases $(n=$ 21). Nearly $85.7 \%$ of Adenocarcinomas were found in lower one third of oesophagus while SCC (Squamous Cell Carcinoma) was most commonly seen in middle one third followed by upper one third of oesophagus, both of which combined together comprises nearly $74 \%$ cases of SCC found in oesophagus.

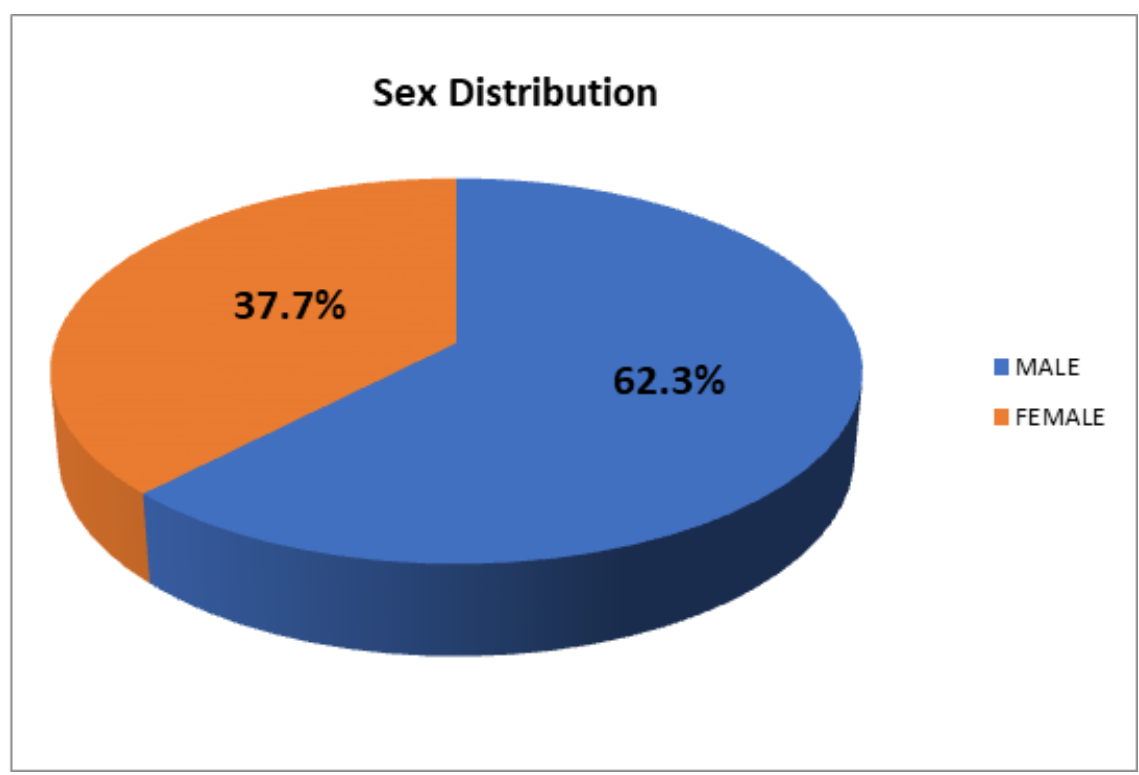

Figure 1: Percentage distribution of males \& females in the study group. 


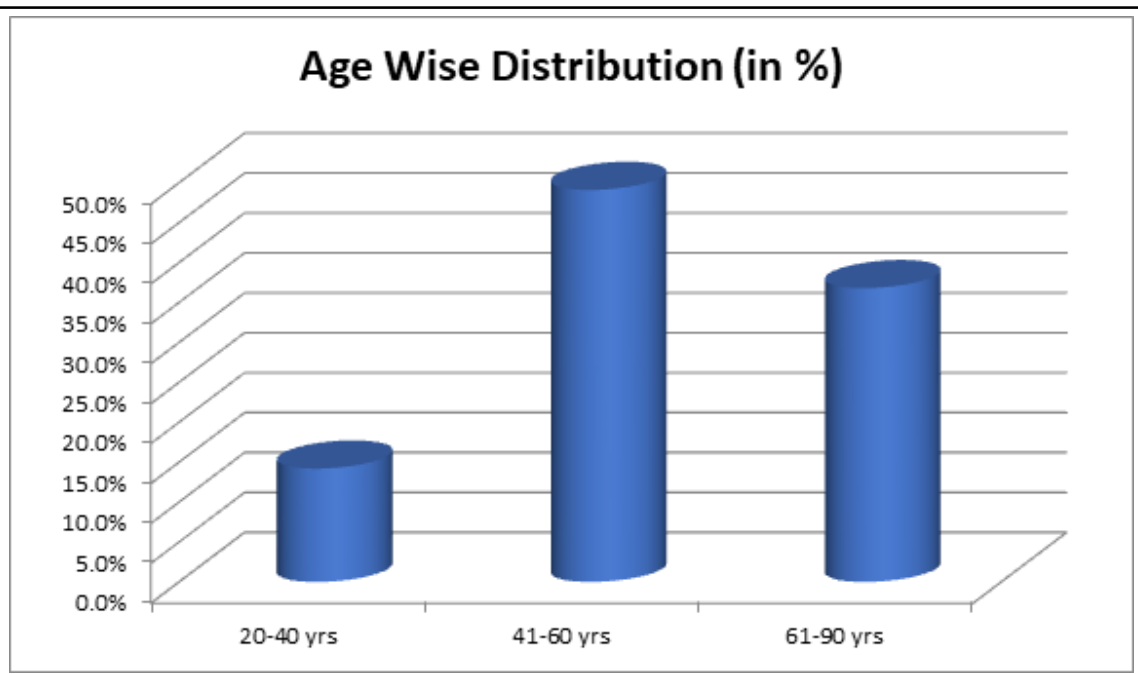

Figure 2: Age wise distribution of cases.

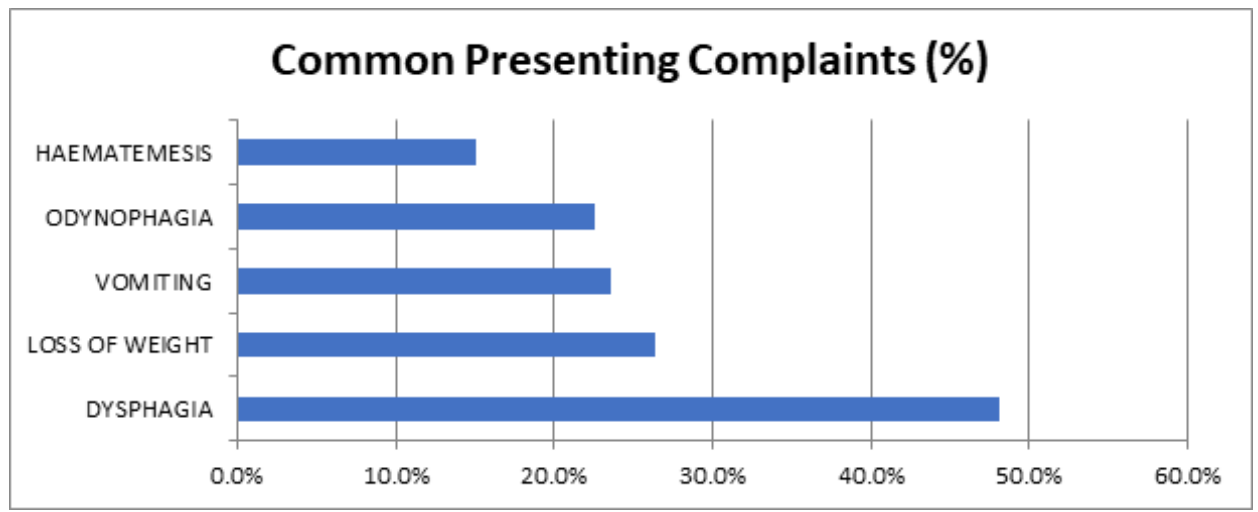

Figure 3: Common presenting Complaints in present study.

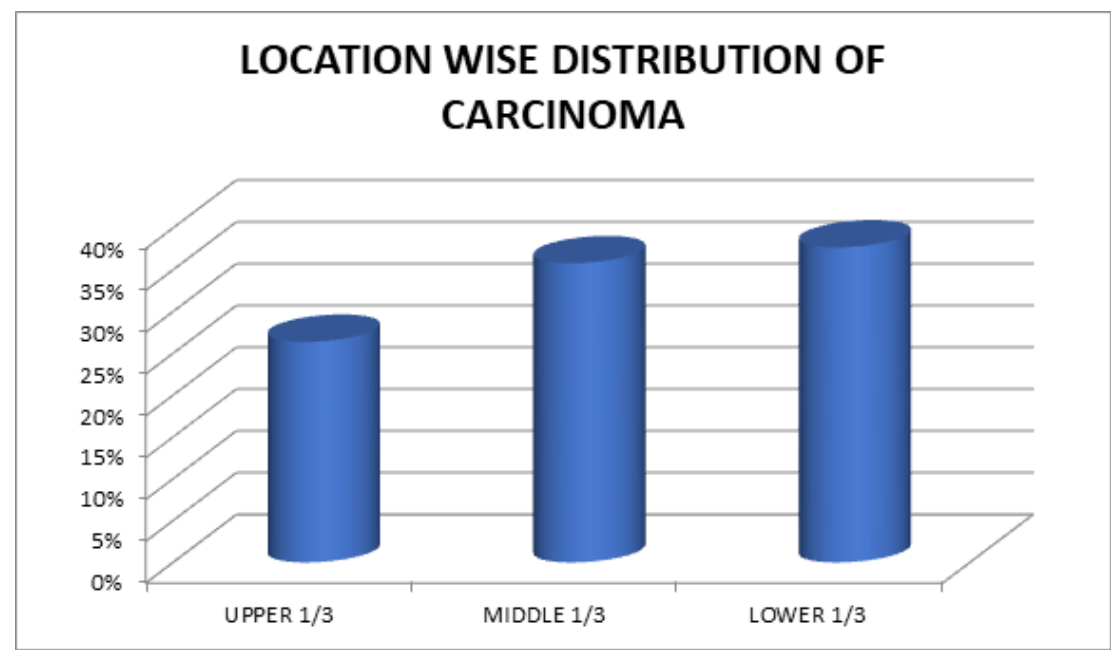

Figure 4: Location wise distribution of Ca oesophagus in this study. 


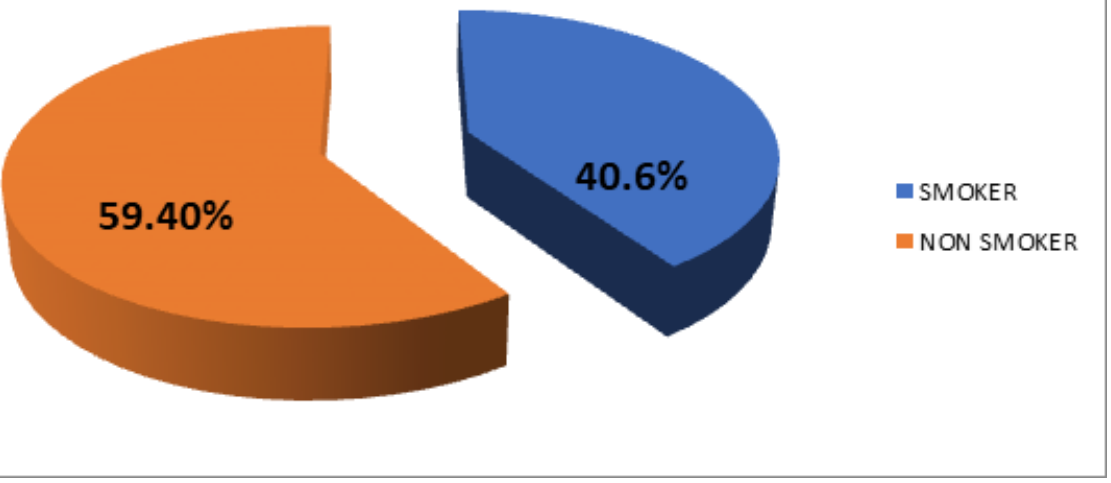

Figure 5: Smoking as a risk factor

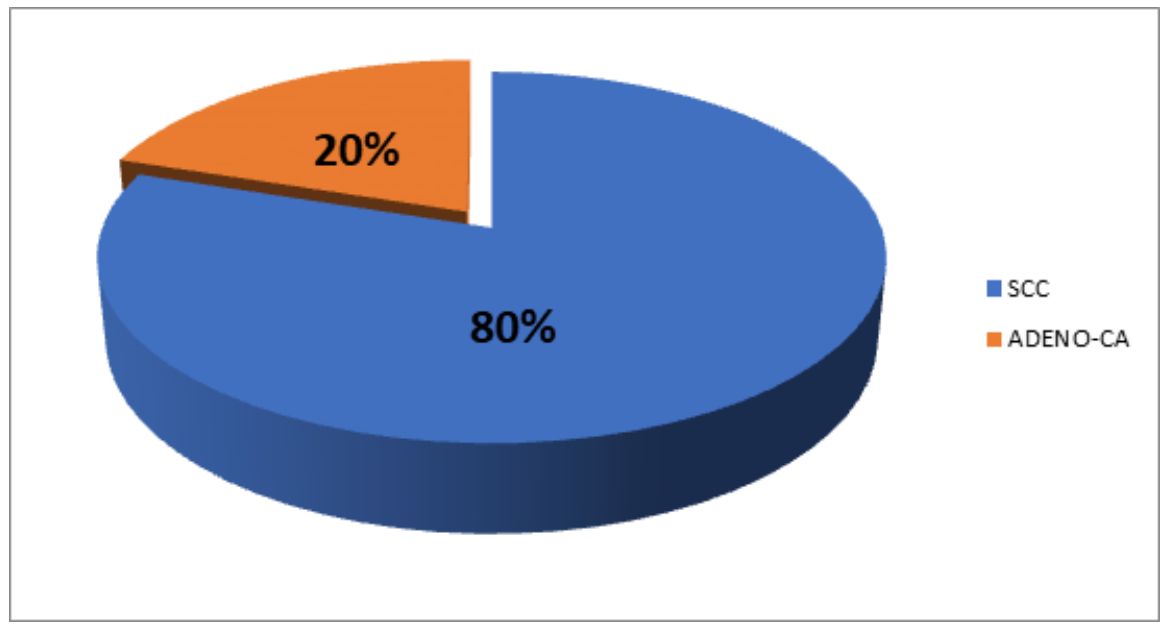

Figure 6: Histopathology of oesophageal carcinoma

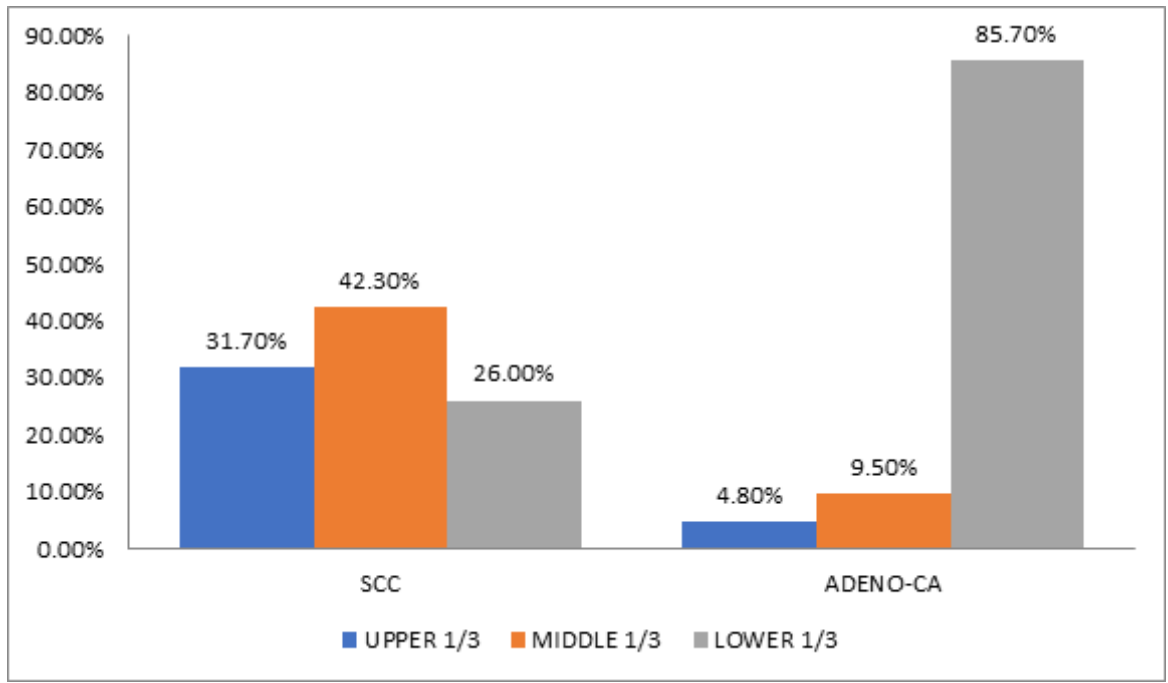

Figure 7: Histopathological diagnosis based on location. 
Annals of International Medical and Dental Research

E-ISSN: 2395-2822 | P-ISSN: 2395-2814

Vol-8, Issue-1 | January-February 2022

DOI: 10.53339 /aimdr.2022.8.1.17

Page no- 124-131 | Section- Research Article (Gastroenterology)

\section{DISCUSSION}

There has been rapid rise in incidence of oesophageal carcinoma worldwide.[8] Oesophageal carcinoma has higher incidence in developing countries compared to developed countries.[] The risk of oesophageal carcinoma increases with age and males have higher risk $(\mathrm{M}: \mathrm{F}=2: 1)$ compared to females.[10] The lifetime risk of developing oesophageal carcinoma in males is 0.8 while in females is 0.3.111] In our study also the male to female ratio was 1.5. Similar findings were reported by other studies like kumar $S$ et al \& Sehgal et al where male to female ratios were reported to be around 2:1. In our study majority (approximately 70\%) of patients were in the age group of 50 years and above.[12,13] Similar finding were reported by study conducted by Kumar $S$ et al where nearly three fourth of patients belongs to age group of above $50 \mathrm{yrs}$.

Amongst the risk factors for oesophageal carcinoma, poor oral hygiene low socioeconomic status, advancing age and smoking were identified. The conventional risk factors like alcoholism, obesity, gastroesophageal reflux disorders have been well described (J Natl Cancer Inst. 2003; 95: 1404-1413) but they were not observed in the present study group. Interestingly, poor oral hygiene and low socioeconomic status had strong association in our study which were not described as strong risk factors for carcinoma esophagus in the literature.

Nearly $48 \%$ of patients in our study presented with dysphagia as a chief complaint which was also one of the most common indication for performing an upper gastrointestinal endoscopy. Similarly, studies performed by other researchers also reported dysphagia to be one of the most common presenting symptom which was seen in upto $80 \%$ of cases of oesophageal carcinoma. $12,14,15]$ Loss of weight was 2 nd most common presentation $(26.4 \%)$ in our study subjects which was closely followed by vomiting \& odynophagia. Other studies have also reported loss weight was $2^{\text {nd }}$ most common presentation but it was present in 60 $70 \%$ of the cases. $[16,17]$ This difference of presentation in comparison to our study might be due to early recognition of oesophageal carcinoma due to early onset dysphagia.

The most common site of ca oesophagus was distal one third followed by middle one third and then upper one third in our study. This finding was similar to results of other studies from india where distal one third was most common site of oesophageal carcinoma. $[12,17]$

On histopathological diagnosis, SCC (squamaous cell carcinoma) was seen in majority $(80 \%)$ of patients while Adenocarcinoma (ADC) was seen in only $20 \%$ cases. Approximately $50 \%$ cases of esophageal cancers are ADCs in Western countries in contrast, SCC continues to be the dominant type in other areas of the world, especially in Asia.18] Similar findings were reported by Kumar et al,[12] from Gujarat, India where $75.8 \%$ of cases had SCC.

In our study nearly $85.7 \%$ of all cases of ADCs were found in distal one third of the oesophagus, whereas SCC was more evenly distributed in oesophagus the common site being middle one third followed by upper one third and then lower one third. Our finding was in concordance with studies by Jemal A et al (Global patterns of cancer incidence \& 
Annals of International Medical and Dental Research

E-ISSN: 2395-2822 | P-ISSN: 2395-2814

Vol-8, Issue-1 | January-February 2022

DOI: 10.53339/aimdr.2022.8.1.17

Page no- 124-131 | Section- Research Article (Gastroenterology)

mortality rates and trends) and Fritz $\mathrm{A}$ et al (International classification of disease for oncology, WHO 2000).[19,20]

\section{CONCLUSIONS}

Our study from North India suggested poor oral hygiene as a strong risk for carcinoma esophagus. Additionally, people with low income have risk of nutritional deficiency

\section{REFERENCES}

1. Zhang Y. Epidemiology of esophageal cancer. World J Gastroenterol. 2013;19(34):5598-5606. doi:10.3748/wjg.v19.i34.5598

2. Bray F, Ferlay J, Soerjomataram I, Siegel RL, Torre LA, Jemal A. Global cancer statistics 2018: GLOBOCAN estimates of incidence and mortality worldwide for 36 cancers in 185 countries. CA Cancer J Clin. 2018;68(6):394-424. doi: 10.3322/caac.21492.

3. Howlader N, Ries LA, Stinchcomb DG, Edwards BK. The impact of underreported Veterans Affairs data on national cancer statistics: analysis using population-based SEER registries. J Natl Cancer Inst. 2009;101(7):533-536. doi:10.1093/jnci/djn517

4. Khuroo MS, Zargar SA, Mahajan R, Banday MA. High incidence of oesophageal and gastric cancer in Kashmir in a population with special personal and dietary habits. Gut. 1992;33(1):11-5. doi: 10.1136/gut.33.1.11.

5. Blot WJ, McLaughlin JK. The changing epidemiology of esophageal cancer. Semin Oncol. 1999;26(5 Suppl 15):2-8.

6. Young JL Jr, Percy CL, Asire AJ, Berg JW, Cusano MM, Gloeckler LA, et al. Cancer incidence and mortality in the United States, 1973-77. Natl Cancer Inst Monogr. 1981;(57):1-187.

7. Parkin DM, Ferlay J, Curado MP, Bray F, Edwards B, Shin HR, et al. Fifty years of cancer incidence: CI5 I-IX. Int J Cancer. 2010;127(12):2918-27. doi: 10.1002/ijc.25517.

8. Pennathur A, Gibson MK, Jobe BA, Luketich JD. Oesophageal carcinoma. Lancet. 2013;381(9864):40012. doi: 10.1016/S0140-6736(12)60643-6. which was another risk factor for carcinoma esophagus. Smoking was another factor in our population with above strong risk factors of carcinoma esophagus. With the background of above, patients having dysphagia and un explained weight loss in the advanced age should always be investigated for carcinoma esophagus.

9. Bray F, Jemal A, Grey N, Ferlay J, Forman D. Global cancer transitions according to the Human Development Index (2008-2030): a population-based study. Lancet Oncol. 2012;13(8):790-801. doi: 10.1016/S1470-2045(12)70211-5.

10. Desai PB, Borges EJ, Vohra VG, Paymaster JC. Carcinoma of the esophagus in India. Cancer. 1969;23(4):979-89. doi: 10.1002/10970142(196904)23:4<979::aid-cncr2820230436>3.0.co;29.

11. Enzinger PC, Mayer RJ. Esophageal cancer. N Engl J Med. 2003;349(23):2241-52. doi: 10.1056/NEJMra035010.

12. Kumar, Santosh et al. Clinical profile of patients presented with esophageal carcinoma in tertiary care teaching medical college of Gujarat, India. Int J Adv Med. 2019;6(2):435-438.

13. Sehgal S, Kaul S, Gupta BB, Dhar MK. Risk factors and survival analysis of the esophageal cancer in the population of Jammu, India. Indian J Cancer. 2012;49(2):245-50. doi: 10.4103/0019-509X.102921.

14. Martin RE, Letsos P, Taves DH, Inculet RI, Johnston $H$, Preiksaitis HG. Oropharyngeal dysphagia in esophageal cancer before and after transhiatal esophagectomy. Dysphagia. 2001;16(1):23-31. doi: 10.1007/s004550000044.

15. Gupta V, Bhardwaj S, Bhagat OK. Pattern of esophageal cancer in tertiary care hospital in North India: a clinicopathological study. Int J Res Med Sci. 2017;5:1405-9.

16. Marin FA, Lamônica-Garcia VC, Henry MA, Burini RC. Grade of esophageal cancer and nutritional status impact on postsurgery outcomes. Arq Gastroenterol. 2010;47(4):348-53. doi: $10.1590 /$ s0004-28032010000400006. 
Annals of International Medical and Dental Research

E-ISSN: 2395-2822 | P-ISSN: 2395-2814

Vol-8, Issue-1 | January-February 2022

DOI: $10.53339 /$ aimdr.2022.8.1.17

Page no- 124-131 | Section- Research Article (Gastroenterology)

17. Mustafa SA, Banday SZ, Bhat MA, Patigaroo AR. Clinico-Epidemiological Profile of Esophageal Cancer in Kashmir. Int J Sci Study. 2016;3:197-202. http:/ /dx.doi.org/10.17354/ijss/2016/84

18. Brown LM, Devesa SS. Epidemiologic trends in esophageal and gastric cancer in the United States. Surg Oncol Clin N Am. 2002;11(2):235-56. doi: 10.1016/s1055-3207(02)00002-9.

19. Jemal A, Center MM, DeSantis C, Ward EM. Global patterns of cancer incidence and mortality rates and trends. Cancer Epidemiol Biomarkers Prev. 2010;19(8):1893-907. doi: 10.1158/1055-9965.EPI-100437.

20. Trott PA. International Classification of Diseases for Oncology. J Clin Pathol. 1977;30(8):782.

Source of Support: Nil, Conflict of Interest: None declared 